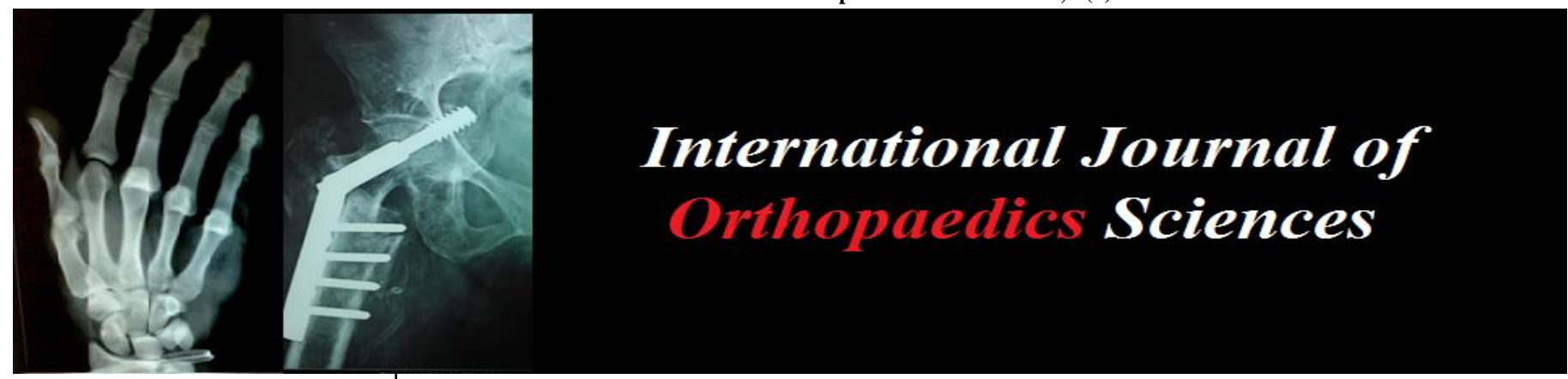

E-ISSN: 2395-1958

P-ISSN: 2706-6630

IJOS 2020; 6(2): 336-339

(C) 2020 IJOS

www.orthopaper.com

Received: 07-01-2020

Accepted: 08-02-2020

Dr. Philipson J Philip

Senior Resident, Govt. T.D

Medical College Alappuzha,

Kerala University of Health

Sciences (KHUS), Kerala, India

Dr. Georgekutty

Additional Professor, Govt. T.D

Medical College Alappuzha,

Kerala University of Health

Sciences (KHUS), Kerala, India

Dr. Manesh Stephen

Assistant Professor, Department of Orthopedics TDMCH, Kerala, India

Dr. Ahamad Shaheel Sultan Senior Resident, Department of Orthopedics TDMCH, Kerala, India

Corresponding Author:

Dr. Georgekutty

Additional Professor, Govt. T.D

Medical College Alappuzha,

Kerala University of Health

Sciences (KHUS), Kerala, India

\section{Functional outcome of floating knee injuries after fixation: A follow up study}

\section{Dr. Philipson J Philip, Dr. Georgekutty, Dr. Manesh Stephen and Dr. Ahamad Shaheel Sultan}

DOI: https://doi.org/10.22271/ortho.2020.v6.i2f.2063

Abstract

Floating knee is a major trauma following high velocity road traffic accidents. We assessed prospectively 25 cases of floating knee injuries that came to Govt. T D MCH casualty over a period of 1-year 6months. Majority had significant associated injuries requiring emergency interventions, multidisciplinary approach and prolonged hospital stay. Majority of cases were male patients around the age of 20-29 year, sustaining high velocity road traffic accidents. Head trauma and Upper Limb fractures were the most common associated injury. FRASER type 1(femur shaft+tibial shaft fracture) was the most common fracture encountered. Zero hour/early fixation seemed to significantly improve post-operative morbidity and less complications. Closed nailing of both tibia and femur were found to be the most successful surgery as evaluated by karlstorm and olerud criteria. On assessment by karlstorm and olerud criteria around $44 \%$ had excellent outcome, $32 \%$ good, $16 \%$ acceptable and $8 \%$ poor.

Keywords: Floating knee, fraser type, multidisciplinary approach, intra-articular injury, karlstorm and olerud criteria

\section{Introduction}

Floating knee is a term used to refer to fractures affecting the ipsilateral tibia and femur ${ }^{[1]}$. These fractures can affect the diaphysis, the metaphysis and even the articular complex, such that the knee becomes "disconnected" from the rest of the limb. Although the exact incidence is unknown. Letts ${ }^{[2]}$ reported incidence of 2.6 percent of all fractures in 1986. The incidence of floating knee is increasing in view of changing lifestyles, high end bikes and poor road conditions leading to high velocity trauma. As floating knee is essentially part of poly trauma, injuries to chest, abdomen and head are common, hence higher morbidity and mortality. Floating knee injuries are almost always associated with soft-tissue injuries, including ligament injuries and vascular injuries. Since it is such a diffuse entity there does not exists a treatment algorithm or specific guidelines for the management of the condition. The choice of implant, surgical procedure, approaches are all surgeon dependent. Surgical stabilization of both the femur and tibia fractures and early rehabilitation of the patient produces best clinical outcome. Diaphyseal fractures have better outcomes as compared to intraarticular fractures. Early papers about floating knee injuries have pointed out the high risk of complications and of permanent disability associated with these fractures McBryde and Blake $1974^{[3]}$. Blake and McBryde ${ }^{[4]}$ in the year 1975 suggested Classification system for floating knee injuries in adults which is still widely used. Fraser ${ }^{[5]}$ in the year 1978 suggested another classification system for the floating knee injuries in adults. In 1977, Karlstorm and Olerud ${ }^{[10]}$, in a review of thirty two patients stressed on the importance of rigid fixation of both the fractures. Karlstorm and Olerud also suggested a universal system to assess the functional results following floating knee injuries. The study was undertaken with the primary objective to assess the functional outcome in case of floating knee injuries after fixation, to find incidence of associated injuries, to assess the time to union, complications and secondary procedures needed to achieve optimal outcome based on different fracture patterns.

\section{Results}

The present study included 25 cases of floating knee injuries admitted in GOVT TD Medical College, Alappuzha. 


\section{Results}

The present study included 25 cases of floating knee injuries admitted in GOVT TD Medical College, Alappuzha. The main aim of treatment of both femur and tibia fractures in floating knee injuries is to make the patient ambulatory and start rehabilitation as early as possible so as to reduce hospital stay, morbidity due to complications such as delayed union, non-union or knee stiffness, infection and associated injuries. Majority of patients were males (92\%). Most common age group were 20 to 29 years of age (28\%). Most common mechanism of injury were high velocity road traffic accident $(96 \%)$. Right side was involved in 14 out of 25 cases $(56 \%)$. There were 16 cases of closed fractures (64\%). Open fractures were 9 out of $25(36 \%)$. There were 15 cases $(60 \%)$ of FRASER type 1, 6 cases (24\%) of type 2A, 2 cases $(8 \%)$ each of type 2B and 2C.Most common implant pair used was NAIL+ NAIL for both femur and tibia; 13 cases (52\%).Single staged surgery was done in 22 cases $(88 \%)$ ). Femur was fixed first in 23 cases $(92 \%)$. Zero-hour fixation was done in 14 out of 25 cases $(56 \%)$. Closed nailing (CRIF) were done in 13 out of 17 cases $(76.47 \%)$ of femoral nailing for closed shaft fractures. CRIF was done in all closed tibial shaft fractures $(100 \%)$. Most common associated injury was head trauma; fractures of upper limb also had the same frequency of occurrence. Most common complication encountered was stiff knee, in 8 cases $(32 \%)$. Most common secondary procedures done were re-debridement ( 8 cases-32\%); followed by arthrolysis (6 cases- $24 \%$ ).

In our study, 18 femur fractures were treated with intra medullary interlocking nail (ILN), One intramedullary supracondylar nail (IMSC), 6 cases with plating. 20 cases achieved union with an average time period of 6 months (range-4-8 months) from the date of definitive fixation. 1 case of plating resulted in mal-union for which corrective osteotomy and repeat plating with bone grafting was done. 2 cases of non-union were encountered, one with chronic osteomyelitis/infected implant for which antibiotic cement rod exchange nailing was done. The patient is under follow up and clinical and radiological signs of union is present at last follow up. Another was a case of atrophic non-union; patient on ILN femur; implant removal done and ring fixator was applied.2 cases of delayed union were present. One case treated with bone grafting and plating; other one is under follow up and showing good results with repeated bone marrow injections.

In our study, 17 tibial fractures were treated with intramedullary interlocking nail, 6 cases with plating, 1 case with multiple percutaneous cancellous screws and 1 with external fixator. 22 case achieved union with an average time period of 5 months (range 4-6 months) with 2 cases of deformity and 1 case of shortening. 1 case of infected nonunion was treated with corticotomy and ring fixator. 2 cases showed delayed union. One required bone grafting and the other one is showing good results with repeated bone marrow injections.

In our study average hospitalization period was 18 days. When both the fractures were closed and treated with early internal fixation, total hospital stay of patient was 10-14 days. Recently aggressive operative treatment has been suggested for floating knee injuries by several investigators. In these reports they emphasized that the operative treatment has resulted in less hospitalization period, fewer complications and better functional outcome than does non-operative treatment. In a study by Anastopopulous [8] 32 cases of floating knee were treated. The tibial fracture treated by unilateral external fixator and femoral fracture was fixed with closed intramedullary nailing, the time of hospitalization ranged from 12 to 105 days (mean 30 days), where as in our study of 25 cases of floating knee all fractures were treated surgically, the time of hospitalization ranged from 10 to 50 days (mean 18 days).

In our study 17 out of 25 patients (68\%) achieved excellent knee range of motion of $0-130^{\circ}$. Knee stiffness, that is loss of knee flexion of more than 30 degrees developed in 2 cases out of the total $15(13.33 \%)$ FRASER Type 1 floating Knee cases, whereas 6 patients out of $10(60 \%)$ cases of FRASER Type 2 floating Knee developed knee stiffness.

Compound fractures of femur and tibia which developed complication such as delayed union, non-union or osteomyelitis lead to knee stiffness even when the fractures were extra articular. Thus, intra articular-extension of either one or both fractures into knee joint was associated with markedly higher incidence of knee stiffness. In Type I floating knee injuries treated with early internal fixation and vigorous early physiotherapy showed better results than cases treated with delayed fixation and prolonged immobilization.

By using Karlstrom \& Olerud criteria the functional outcome in our study was excellent in $11(44 \%)$ patients; good in 8 (32\%) patients; acceptable in $4(16 \%)$ patients and poor in 2 $(8 \%)$ patients. In comparison to Karlstrom G., Olerud $S^{[6]}$. study of 32 cases in which overall excellent to good results were obtained in $86 \%$, our study shows $76 \%$ of overall excellent to good results. Whereas study by Veith et al. ${ }^{[7]}$ had $72 \%$ excellent to good and Anastopoulas et al. ${ }^{[20]}$ had $81 \%$ overall excellent to good results. These results are much better than conservative series of Fraser et al. ${ }^{[9]}$ which shows $29 \%$ excellent to good results.

Table 1: Comparative Results of Floating Knee Injuries

\begin{tabular}{|c|c|c|}
\hline Series & Excellent-Good & Acceptable Poor \\
\hline Karlstrom Olerud et al. ${ }^{[6]}$ & $86 \%$ & $14 \%$ \\
\hline Fraser et al. ${ }^{[5]}$ & $29 \%$ & $71 \%$ \\
\hline Veith et al. ${ }^{[7]}$ & $72 \%$ & $28 \%$ \\
\hline Anastopoulas et al. ${ }^{[8]}$ & $81 \%$ & $19 \%$ \\
\hline Our Series & $76 \%$ & $24 \%$ \\
\hline
\end{tabular}

Results of Type II fractures are poor than that of fractures without involvement of knee joint. Rethnam $\mathrm{V}^{[13]}$. concluded that the prognostic fractures in floating knee injuries include the associated injuries and the type of fracture whether it is open, intra-articular or comminuted. On comparing results of type II floating knee injuries, $24 \%$ excellent to good in series by Adamson et al. ${ }^{[9]}$ our results are excellent to good in $50 \%$ cases; whereas Hung et al. ${ }^{[11]}$ had $23.8 \%$ excellent to good results in their study. Yokoyama ${ }^{[12]}$ concluded that involvement of knee joint, the severity grade of soft tissue injury represent significant risk factor of poor outcome of floating knee injuries.

\section{Comparative Results of Type II Floating Knee Injuries}

Table 2: Comparative Results of Type II Floating Knee Injuries

\begin{tabular}{|c|c|c|}
\hline Series & Excellent-Good & Acceptable Poor \\
\hline Adamson et al. ${ }^{[9]}$ & $24 \%$ & $76 \%$ \\
\hline Hung et al. ${ }^{[11]}$ & $23.8 \%$ & $76.2 \%$ \\
\hline Our Series & $50 \%$ & $50 \%$ \\
\hline
\end{tabular}




\section{Complications}

Table 3: No of Cases- Complications

\begin{tabular}{|c|c|c|c|}
\hline S. No. & Complication & No. of Cases & Percentage \\
\hline 1. & Shock & 5 & $20 \%$ \\
\hline 2. & Fat Embolism & 4 & $16 \%$ \\
\hline 3. & Compartment Syndrome & 1 & $4 \%$ \\
\hline 4. & Mal Union & 1 & $4 \%$ \\
\hline 5. & Non Union & 3 & $12 \%$ \\
\hline 6. & Delayed union & 4 & $16 \%$ \\
\hline 7. & Local infection & 4 & $16 \%$ \\
\hline 8. & Chronic osteomyelitis & 5 & $20 \%$ \\
\hline 9. & Knee Stiffness & 8 & $32 \%$ \\
\hline 10. & Shortening $>1$ cm & 4 & $16 \%$ \\
\hline 11. & Deformity & 3 & $12 \%$ \\
\hline 12. & Implant Loosening & 1 & $4 \%$ \\
\hline
\end{tabular}

\section{Discussion}

Due to increase in motor vehicle accidents, patients with multiple system involvements are increasing in number. During the treatment of such patients, there are two major considerations. First is a systemic injury with body response to injury complicating the situation and second is problem associated with concomitant fractures. We had 28 cases of floating knee injuries arrived in our casualty in GOVT TD medical college, Alappuzha. There were 3 deaths out of 28 cases of floating knee injury (10.7\%). All these cases had multiple system injuries, they were haemodynamically unstable on arrival and all the three deceased while undergoing resuscitation in ER. Most of the patients were between 20-40 years age group indicating that it is an injury occurring commonly in young adults. The floating knee injuries were treated aggressively with surgical methods by Karlstrom and Olerud [6] in 1977. Aggressive operative treatment has been suggested for floating knee injuries by several investigators. The operative treatment has resulted in less hospitalization, less systemic complications and better functional outcome than non-operative treatment. In the literature, the average length of hospitalization in most operative series was from 30-36 days. Karlstrom and olerud reported the period of hospitalization was 11.5 weeks on an average when both fractures were treated surgically. Gregory et al. ${ }^{[22]}$ reported hospitalization of 17 days. In our study average hospitalization period was 18 days. Omer et al. reported $31 \%$ incidence of infection in nonoperatively treated patients. Fraser et al. ${ }^{[5]}$ reported higher infection rate in those treated with stabilization of both the fractures surgically than those treated non-operatively (20\% Vs. $8 \%$ ). Veith et al. ${ }^{[7]}$ reported only $5 \%$ infection rate when any one of the fracture was surgically stabilized. Mc Andrew and Gregory et al. ${ }^{[10]}$ respectively reported deep infection in $22 \%$ of tibial fractures and $11 \%$ in femur fractures. In our series deep infection rate was $16 \%$ in tibial fractures and $4 \%$ in femur fracture and is comparable to previous studies. Karlstrom and olerud [6] reported healing time of around 20 weeks whereas according to Adamson et al. ${ }^{[21]}$ it was 39 weeks for femur and 37.5 weeks for tibia. In our series average healing time was around 26 weeks for femur and 21 weeks for tibia which is comparable to previous studies. By using Karlstrom and Olerud criteria the functional outcome was excellent in 11 patients $(44 \%)$, good in 8 patients $(32 \%)$, acceptable in 4 patients $(16 \%)$ and poor in 2 patients $(8 \%)$. Thus excellent to good results were obtained in $76 \%$ patients as compared to $86 \%$ in karlstrom and olerud ${ }^{[10]}$ series, $72 \%$ in Veith ${ }^{[7]}$ series and $81 \%$ in Anastropopulas ${ }^{[8]}$ series. These results are better when compared to non-operative treatment according to Fraser et al. which is ${ }^{[29]}$.

\section{Conclusion}

Floating knee is a major trauma following high velocity road traffic accidents. Majority will have significant associated injuries requiring emergency interventions, multidisciplinary approach and prolonged hospital stay. Aggressive wound debridement with early stabilization provide good functional outcome in treatment of floating knee injury. Zero-hour fixation of at least one fracture must be a strict protocol in emergency management. Femur should always be given preference in order of fixation. Early debridement and stabilisation, early rehabilitation could improve the functional recovery of floating knee injuries especially for fractures with intra-articular involvement (Our study had $50 \%$ excellent to good outcome in FRASER TYPE 2 injuries; which is almost double the rate seen in literatures (24\% in Adamson et al. ${ }^{[21]}$; $23.8 \%$ in Hung et al. ${ }^{[33]}$ series)). Internal fixation of fractures permits early mobilization of the knee joint with good functional outcome.Even though early fixation and early mobilization seemed to significantly improve functional outcome, the complication rates both trauma/surgeries associated as well as psychosocial complications still remains high even at this time of well facilitated high quality medical care.

\section{Pre Op}

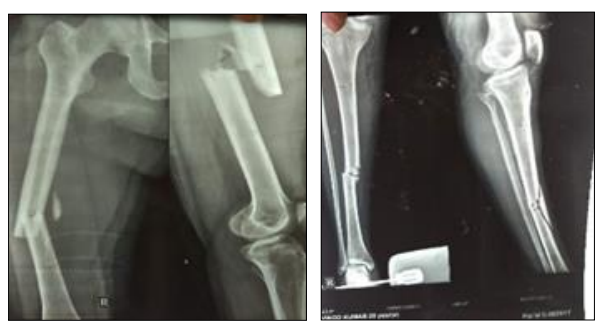

\section{At 5 months follow up after fixation}
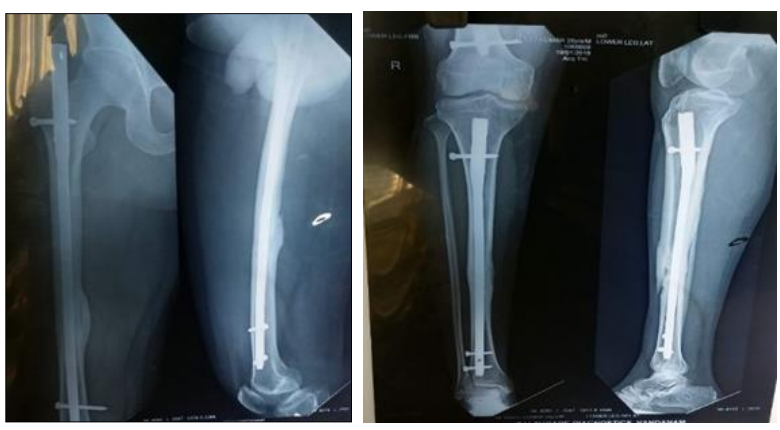

\section{Range of motion}
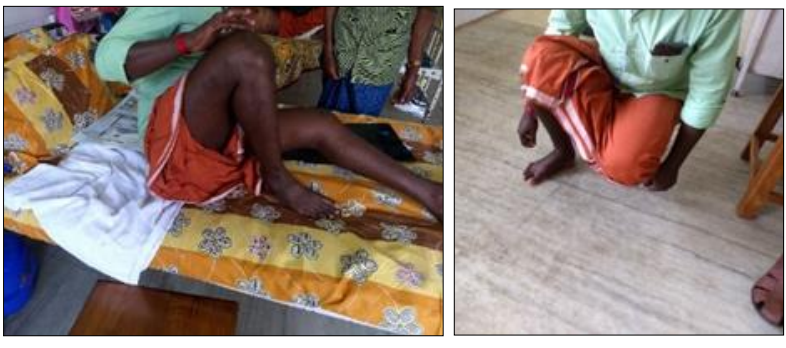

Fig 1: 27-year-old male with road traffic accident sustained closed Fraser type 1 floating knee injury surgically corrected with closed nailing of both tibia and femur 


\section{Knee stiffness at 9 months}

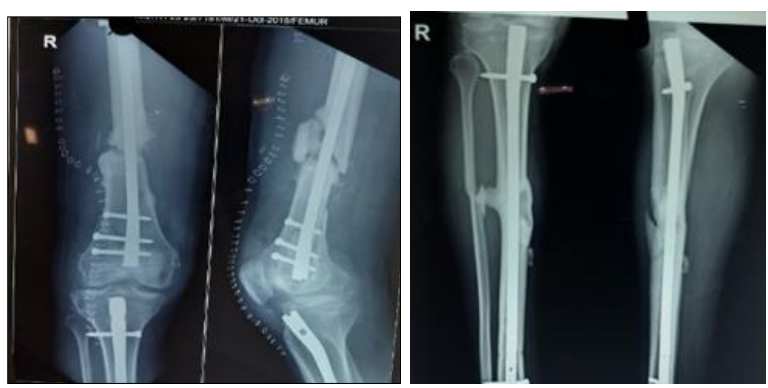

Post Arthrolysis increase in flexion
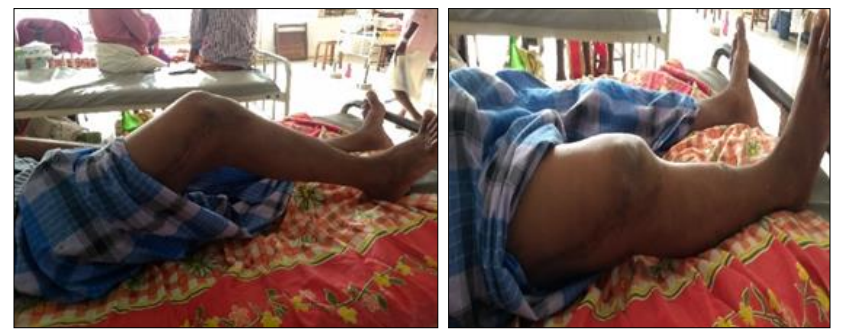

Post Arthrolysis increase in flexion

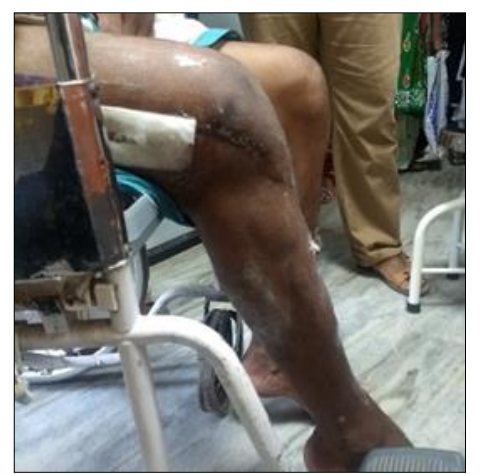

Fig 2: Fraser type 2b Floating knee injury with GA TYPE 2 open fracture fixed with intramedullary supracondylar nail (IMSC) -Open nailing and ILN TIBIA

\section{References}

1. Muñoz Vives J, Bel J-C, Capel Agundez A, Chana Rodríguez F, Palomo Traver J, Schultz-Larsen M et al. The floating knee: a review on ipsilateral femoral and tibial fractures. EFORT Open Rev. 2016; 1(11):375-82.

2. Letts M, Vincent N, Gouw G. The "floating knee" in children. J Bone Joint Surg Br. 1986; 68-B(3):442-6.

3. Mcbryde A Jr. The floating knee-Ipsilateral fracture of the femur and tibia. J Bone Jt Surg. 1974; 56:1309.

4. Blake R, McBryde JA. The floating knee: Ipsilateral fractures of the tibia and femur. South Med J. 1975; 68(1):13-6.

5. Fraser R, Hunter G, Waddell J. Ipsilateral fracture of the femur and tibia. J Bone Joint Surg Br. 1978; 60B(4):510-5.

6. Karlström G, Olerud S. Ipsilateral fracture of the femur and tibia. J Bone Joint Surg Am. 1977; 59(2):240-3.

7. Veith RG, Winquist RA, Hansen JS. Ipsilateral fractures of the femur and tibia. A report of fifty-seven consecutive cases. J Bone Joint Surg Am. 1984; 66(7):991-1002.

8. Anastopoulos G, Assimakopoulos A, Exarchou E, Pantazopoulos Th. Ipsilateral fractures of the femur and tibia. Injury. 1992; 23(7):439-41.

9. Adamson GJ, Wiss DA, Lowery GL, Peters CL. Type II floating knee: ipsilateral femoral and tibial fractures with intraarticular extension into the knee joint. J Orthop Trauma. 1992; 6(3):333-9.

10. Gregory P, DiCicco J, Karpik K, DiPasquale $T$, Herscovici D, Sanders R. Ipsilateral Fractures of the Femur and Tibia: Treatment with Retrograde Femoral Nailing and Unreamed Tibial Nailing. J Orthop Trauma. 1996; 10(5):309.

11. Hung S-H, Chen T-B, Cheng Y-M, Cheng N-J, Lin S-Y. Concomitant Fractures of the Ipsilateral Femur and Tibia with Intra-articular Extension into the Knee Joint. J Trauma Acute Care Surg. 2000; 48(3):547.

12. Yokoyama K, Tsukamoto T, Aoki S, Wakita R, Uchino $\mathrm{M}$, Noumi T et al. Evaluation of functional outcome of the floating knee injury using multivariate analysis. Arch Orthop Trauma Surg. 2002; 122(8):432-5.

13. Rethnam U, Yesupalan RS, Nair R. Impact of associated injuries in the Floating knee: A retrospective study. BMC Musculoskelet Disord. 2009; 10(1):7. 